\title{
Tumor primário pulmonar metastático em três cães
}

\section{Metastatic primary lung tumor in three dogs}

\author{
Elisângela Olegário da Silva'; Kerriel Thandile Green²; \\ Danilo Gouveia Wasques 3 ; Antônio Carlos Faria dos Reis ${ }^{4}$; \\ Ana Paula Frederico Rodrigues Loureiro Bracarense ${ }^{4^{*}}$
}

Resumo

Tumores primários pulmonares (TPP) são incomuns em cães e ocasionalmente metastatizam para órgãos distantes. Relatam-se três casos de TPP com origem epitelial em cães, diagnosticados pós-morte por meio do exame histopatológico e imuno-histoquímico. O caso 1 apresentou sinais clínicos inespecíficos, os casos 2 e 3 apresentaram sinais clínicos de alterações respiratórias e no exame radiográfico visualizouse nódulo(s) pulmonar. Os casos 1 e 3 foram diagnosticados como adenocarcinoma papilar pulmonar com metástase nos linfonodos mediastínicos, fígado, adrenal direita (caso 1) e, pericárdio e linfonodos mediastínicos (caso 3). O caso 2 apresentou carcinoma de células escamosas pulmonar com metástase no coração, rins e glândula perianal. Não há relatos prévios de metástase de TPP epitelial no pericárdio, coração, fígado, rim e glândula perianal. Os três tumores tiveram marcação positiva para o anticorpo anti-pancitoqueratina e negativa para o anticorpo anti-vimentina. Em cães com TPP, o estadiamento clínico TNM e a classificação e graduação histológicas são fundamentais para a determinação do tratamento e prognóstico.

Palavras-chave: Carcinoma pulmonar, metástases, imuno-histoquímica

\begin{abstract}
Primary lung tumors (PLT) are uncommon in dogs and occasionally metastasize to distant organs. This report describes three cases of PLT in dogs with epithelial origin, diagnosed post mortem through histopathology and immunohistochemistry. Case one presented nonspecific symptoms while the second and third cases presented respiratory alterations and radiographic exams revealed the presence of pulmonary nodule(s). Case 1 was diagnosed as a pulmonary papillary adenocarcinoma with metastasis to the mediastinal lymph nodes, liver and right adrenal gland. Case 2 was a pulmonary squamous cell carcinoma with metastasis to the heart, kidneys and perianal gland, whereas Case 3 was diagnosed as pulmonary papillary adenocarcinoma with metastasis to the pericardium and mediastinal lymph nodes. There is no previous report of epithelial TPP metastasis to pericardium, heart, liver, kidney and perianal gland. The three tumors showed positive immunostaining for the anti-pan-cytokeratin antibody and negative immunostaining for the anti-vimentin antibody. In dogs with PLT, the TNM clinical staging and histological classification and grading are fundamental for therapeutic planning and prognosis determination.
\end{abstract}

Key words: Pulmonary carcinoma, metastasis, immunohistochemistry

\footnotetext{
1 Discente de Mestrado do Programa de Pós-Graduação em Ciência Animal, Universidade Estadual de Londrina, UEL, Londrina, PR. E-mail: elivet02@gmail.com

2 Residente de Patologia Animal, UEL, Londrina, PR. E-mail: ktgvet@yahoo.com

3 Médico Veterinário Autônomo. São Paulo, SP. E-mail: danilogw@gmail.com

4 Profs. Drs. do Dept ${ }^{\mathrm{o}}$ de Medicina Veterinária Preventiva, DMVP/UEL, Londrina, PR. E-mail: reis@uel.br; anaue102@yahoo. com.br

* Autor para correspondência
} 


\section{Introdução}

O pulmão é ricamente vascularizado e frequentemente alvo de metástases, no entanto, os tumores primários pulmonares (TPP), diferente do que ocorre em humanos, são incomuns em cães e gatos, e pouco relatados em outras espécies domésticas (WILSON; DUNGWORTH DL, 2002; WITHROW, 2007). Em cães representam cerca de $1 \%$ de todos os tumores que os acometem. A média de idade dos animais afetados é de 10 anos, sendo reportada uma maior incidência nas raças Labrador Retriever, Springer Spaniel Inglês, Boxer, Doberman Pinscher, Pastor Australiano, Setter Irlandês e Bernese Mountain Dog (OGILVIE et al., 1989; McNIEL et al., 1997; WITHROW, 2007). Não há predisposição sexual, no entanto alguns autores observaram uma maior ocorrência em fêmeas (McNIEL et al., 1997; POLTON et al., 2008).

Os sinais clínicos são variáveis em cães e muitas vezes inespecíficos. Tosse crônica não responsiva a antibióticos é o mais frequentemente observado. Intolerância ao exercício, taquipneia, dispneia e claudicação podem ocorrer (OGILVIE et al., 1989; McNIEL et al., 1997; NELSON; SELLON, 2005). Outras complicações observadas são efusão pleural e hemotórax (McNIEL et al., 1997; WITHROW, 2007). As síndromes paraneoplásicas são pouco reconhecidas em cães com TPP, sendo a osteopatia hipertrófica a mais relatada (OGILVIE et al., 1989; McNIEL et al., 1997; WITHROW, 2007).

A radiografia simples torácica é essencial no diagnóstico e estadiamento clínico TNM (tumor, nodes, metastases) dos TPP. Outros exames auxiliares são a tomografia computadorizada, toracoscopia, broncoscopia, lavado transtraqueal e broncoalveolar, análise de líquido pleural e aspirado citológico por agulha fina (McNIEL et al., 1997; WITHROW, 2007). No entanto, o diagnóstico definitivo é obtido somente por meio do exame histopatológico (WILSON; DUNGWORTH, 2002; NELSON; SELLON, 2005).
Assim como em humanos, a maioria dos TPP em cães é maligno (WILSON; DUNGWORTH, 2002; VOLLMER et al., 2010). Predominam os tumores epiteliais, podendo ter origem hilar ou broncoalveolar. Os tumores hilares frequentemente apresentam-se como massas solitárias, no lobo caudal direito, e são classificados histologicamente como adenocarcinomas, carcinomas de células escamosas e carcinomas adenoescamosos. Os tumores broncoalveolares, normalmente multifocais, envolvem vários lobos pulmonares e são classificados como carcinomas e adenocarcinomas. Outros tumores primários que podem acometer os pulmões são adenomas, osteossarcoma, fibrossarcoma, condrossarcoma, sarcoma indiferenciado, histiocitose maligna, granulomatose linfomatóide, tumor de célula granular, tumor neuroendócrino, hemangiossarcoma e mesotelioma (OGILVIE et al., 1989; WILSON; DUNGWORTH, 2002; POLTON et al., 2008).

O tratamento de escolha é a excisão cirúrgica do tumor. A quimioterapia e a radioterapia podem ser utilizadas como adjuvantes. O estadiamento clínico TNM, a classificação e graduação histológica são fatores que influenciam no prognóstico do animal (OGILVIE et al., 1989; McNIEL et al., 1997).

Os TPP se disseminam via vasos sanguíneos, linfáticos e por via transcelômica. Em humanos, os principais órgãos acometidos pelas metástases são os linfonodos, fígado, adrenal, ossos e cérebro (WOODS; KORETZ, 1990). Em gatos, os TPP são mais agressivos e tendem a metastatizar com maior frequência, principalmente para os dígitos (WITHROW, 2007). Em cães, metástases de TPP epitelial foram relatadas em linfonodos mediastínicos, tecidos torácicos (não especificados), olhos, costelas, adrenais, cérebro e intrapulmonares (OGILVIE et al., 1989; McNIEL et al., 1997; WILSON; DUNGWORTH, 2002; WITHROW, 2007). Não há relatos especificando metástases de TPP epitelial em pericárdio, coração, fígado, rins e glândula perianal. 


\section{Relatos de Casos}

Os casos apresentados são de cães atendidos no Hospital Veterinário e encaminhados para exame necroscópico no Laboratório de Patologia Animal, ambos situados na Universidade Estadual de Londrina, Londrina-PR. Os três animais foram submetidos ao exame necroscópico padrão nos anos de 2009, 2010 e 2011. Fragmentos das lesões foram colhidos e fixados em solução de formalina tamponada a 10\%. Após a fixação, foram submetidos ao processamento histológico padrão para avaliação das alterações microscópicas. O exame imuno-histoquímico para os anticorpos antivimentina (clone V9, 1:100, Invitrogen ${ }^{\circledR}$ ) e antipancitoqueratina (clones AE1/AE3 e 5D3, 1:100, Biocare Medical ${ }^{\circledR}$ ) foi realizado em fragmentos dos nódulos pulmonares. Protocolos, controles positivos (carcinoma mamário para pancitoqueratina e sarcoma para vimentina) e negativos foram utilizados conforme as orientações dos fabricantes.

\section{Caso 1}

Cão, fêmea, 14 anos de idade, sem raça definida, com histórico de apatia e hiporexia há três meses. Ao exame clínico observou-se que o animal estava desidratado e com febre. Os exames laboratoriais revelaram uma leucocitose com 40.270 células composta por segmentados $(82 \%)$, bastonetes (4\%), linfócitos $(6 \%)$ e monócitos $(2 \%)$. O animal foi submetido à antibioticoterapia e fluidoterapia, no entanto progrediu para decúbito lateral e anorexia. Diante do agravamento do quadro clínico, o proprietário optou pela eutanásia. No exame necroscópico observou-se a presença de nódulos difusos pelos lobos pulmonares (1,0 a 1,5 cm de diâmetro), amarelo-esbranquiçados com consistência firme e antracose. Os linfonodos mediastínicos apresentavam-se aumentados, firmes e ao corte com micronódulos esbranquiçados $(0,2$ a $0,5 \mathrm{~cm})$. No fígado, presença de nódulos esbranquiçados e firmes, umbilicados, com distribuição multifocal pelos lobos $(1,0$ a 2,0 $\mathrm{cm}$ de diâmetro). $\mathrm{Na}$ adrenal direita observou-se nódulo esbranquiçado com $0,5 \mathrm{~cm}$ de diâmetro em medular. A avaliação microscópica do pulmão evidenciou proliferação de células epiteliais cuboides a colunares dispostas predominantemente em arranjos papilares e entremeadas por discreto a moderado estroma colagenoso, pouco circunscrita e infiltrativa em parênquima pulmonar. As células apresentavam discreto a moderado citoplasma basofílico, núcleo ovalado, um ou mais nucléolos conspícuos e moderada anisocariose. Quantificouse média de 2,6 figuras de mitose por campo de maior aumento (400x). A neoplasia continha extensas áreas de necrose e hemorragia. Nos linfonodos mediastínicos (Figura 1G), fígado e adrenal observou-se proliferação de células epiteliais neoplásicas com características similares às do pulmão. Necrose e hemorragia também foram observadas nos focos metastáticos. O tumor pulmonar teve marcação positiva para o anticorpo anti-pancitoqueraina e negativa para o anticorpo anti-vimentina. O diagnóstico definitivo foi de adenocarcinoma papilar pulmonar com metástase em linfonodos mediastínicos, fígado e adrenal direita. 
Figura 1. A- Caso 2: carcinoma de células escamosas pulmonar. Áreas esbranquiçadas com formato serpentinoso difusas pelo pulmão. B- Caso 2: metástase de carcinoma de células escamosas pulmonar em coração. Presença de áreas e pequenos nódulos esbranquiçados (setas). C- Caso 2: carcinoma de células escamosas pulmonar. Células epiteliais neoplásicas dispostas em pequenas ilhas entremeadas por discreto estroma colagenoso (H\&E, objetiva de 20X). D- Caso 3: adenocarcinoma papilar pulmonar. Células epiteliais neoplásicas dispostas em arranjos papilares entremeadas por abundante estroma colagenoso (H\&E, objetiva de 20X). E- Caso 2: metástase de carcinoma de células escamosas pulmonar em coração. Presença de células epiteliais neoplásicas dispostas em pequenos cordões e grupos invadindo a musculatura cardíaca (H\&E, objetiva de 20X). F- Caso 2: metástase de carcinoma de células escamosas em glândula perianal. Presença de células epiteliais neoplásicas dispostas em ilhas entremeando as glândulas perianais (H\&E, objetiva de 20X). G- Caso1: metástase de adenocarcinoma papilar pulmonar em linfonodo mediastínico. Proliferação de células epiteliais neoplásicas circundando um folículo linfóide (H\&E, objetiva de 10X). H- Caso 2: células epiteliais neoplásicas com marcação positiva citoplasmática para o anticorpo anti-pancitoqueratina (Imuno-histoquímica, objetiva de 20X).

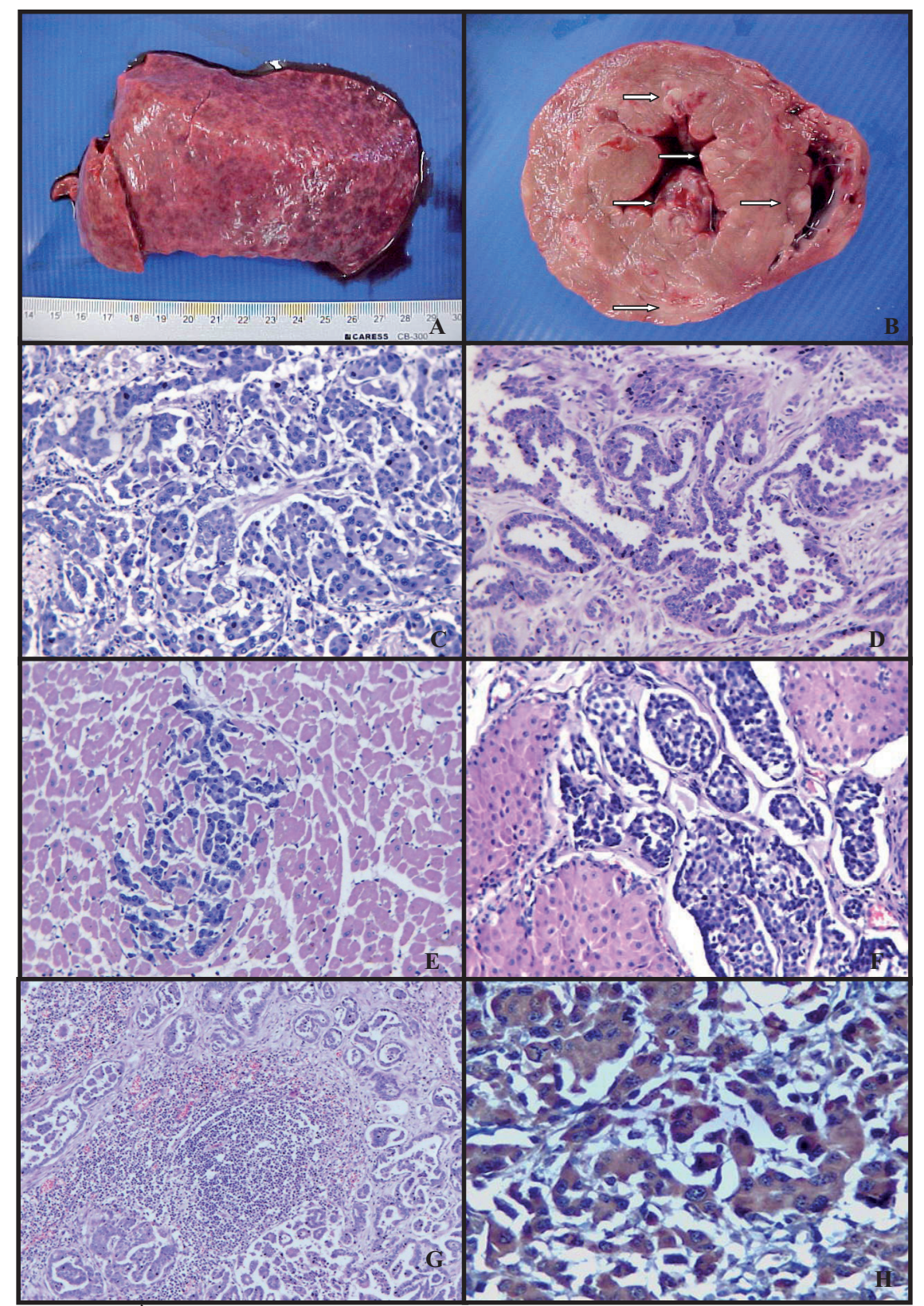

Fonte: Elaboração dos autores. 


\section{Caso 2}

Cão, macho, 11 anos de idade, sem raça definida, com histórico de apatia, vômito, dificuldade respiratória e cansaço fácil há três dias. Ao exame clínico constatou-se que o animal apresentava respiração abdominal superficial com crepitação e posição ortopneica. Os exames laboratoriais revelaram uma leucocitose com 18.900 células composta por segmentados $(88 \%)$, bastonetes (2\%), linfócitos (7\%) e monócitos (3\%). No exame radiográfico visualizou-se padrão pulmonar broncointersticial generalizado e pequenas nodulações pelo parênquima pulmonar. $\mathrm{O}$ animal foi submetido à fluidoterapia e tratamento com antibiótico e antiemético, porém veio a óbito após doze horas de internamento. No exame necroscópico observaram-se áreas esbranquiçadas em padrão serpentinoso pelos lobos pulmonares (Figura 1A) e nódulos esbranquiçados e firmes $(0,2$ a $0,5 \mathrm{~cm}$ de diâmetro). Verificou-se ainda a presença de nódulos esbranquiçados no coração $(0,2$ a $0,5 \mathrm{~cm}$ de comprimento) (Figura 1B), nódulo perianal $(1,5 \mathrm{~cm}$ de diâmetro) e pequenos nódulos esbranquiçados na cortical de ambos os rins $(0,3$ a $0,5 \mathrm{~cm}$ de diâmetro). $\mathrm{Na}$ microscopia pulmonar observouse proliferação de células epiteliais neoplásicas dispostas em ilhas e pequenos cordões, entremeados por discreto estroma colagenoso, não circunscrita e invasiva no parênquima pulmonar (Figura 1C). As células apresentavam moderado a amplo citoplasma basofílico, núcleo ovalado e vesiculoso, um ou mais nucléolos conspícuos e moderada a acentuada anisocariose. Constatou-se uma média de 2,8 figuras de mitose por campo de maior aumento (400X), extensa necrose e hemorragias multifocais, e moderado infiltrado linfoplasmocitário entremeando as células neoplásicas. No coração (Figura 1E), glândula perianal (Figura 1F) e rins evidenciou-se proliferação epitelial neoplásica com características similares às observadas no pulmão. Invasividade, necrose e hemorragia foram observadas nos focos metastáticos. O tumor pulmonar teve marcação positiva para o anticorpo anti-pancitoqueratina (Figura $1 \mathrm{H}$ ) e negativa para o anticorpo anti-vimentina. $\mathrm{O}$ diagnóstico definitivo foi de carcinoma de células escamosas pulmonar com metástase em coração, rins e glândula perianal.

\section{Caso 3}

Cão, fêmea, oito anos de idade, sem raça definida, com histórico de tosse seca e febre há uma semana. No exame clínico apresentou posição ortopneica e dispneia expiratória. Os exames laboratoriais revelaram uma leucocitose com 20.000 células composta por segmentados $(90 \%)$ e linfócitos (10\%). Ao exame radiográfico visualizouse estrutura semicircular com aproximadamente $3 \mathrm{~cm}$ de diâmetro cranial ao coração e ventral à traquéia, além de efusão pleural. $O$ exame citopatológico da efusão revelou células mesoteliais reativas. $\mathrm{O}$ animal foi internado e submetido à antibioticoterpia, no entanto os sinais clínicos respiratórios se agravaram e o animal veio a óbito. No exame necroscópico observou-se presença de nódulo de $4 \mathrm{~cm}$ de diâmetro, esbranquiçado e consistência firme na periferia do lobo caudal direito. Também foram observadas áreas elevadas e esbranquiçadas $(0,5 \mathrm{a} 1 \mathrm{~cm})$ em pericárdio, aumento dos linfonodos mediastínicos e aproximadamente $130 \mathrm{~mL}$ de líquido serossanguinolento em tórax. O exame histopatológico do nódulo pulmonar revelou proliferação de células epiteliais dispostas predominantemente em arranjos papilares entremeadas por abundante estroma colagenoso, moderadamente circunscrita e invasiva em estroma pulmonar e pleura visceral (Figura 1 D). As células apresentavam discreto citoplasma levemente eosinofílico, núcleo ovalado, nucléolo conspícuo e moderada a acentuada anisocariose. Quantificouse média de 1,5 figuras de mitose por campo de maior aumento (400X). No pericárdio e linfonodos mediastínicos observou-se proliferação epitelial neoplásica com características similares as do nódulo pulmonar. O tumor pulmonar teve marcação positiva para o anticorpo anti-pancitoqueratina e 
negativa para o anticorpo anti-vimentina. Diante dos achados histopatológicos, o tumor foi diagnosticado como adenocarcinoma papilar pulmonar com metástase em pericárdio e linfonodos mediastínicos.

O TPP é um dos tumores de maior incidência em humanos devido ao tabagismo e exposição a diversos fatores carcinogênicos. A ocorrência em cães é incomum, mas estudos mostram que cães expostos a fumaça de cigarro, agentes radioativos e poluição desenvolveram TPP. Além disso, os TPP caninos apresentam comportamento biológico e características moleculares semelhantes ao homem. (GILLETT et al., 1992; REIF et al., 1992).

Os sinais clínicos podem ser inespecíficos como no caso 1 , mas em geral estão associados a alterações respiratórias como as observadas nos casos 2 e 3 (OGILVIE et al., 1989; McNIEL et al., 1997). Nos três casos observou-se leucocitose neutrofílica. Tal achado é relatado em gatos com TPP, mas em cães não há dados sobre sua ocorrência (WILSON; DUNGWORTH, 2002). O exame radiográfico é uma ferramenta chave na triagem de animais com neoplasia pulmonar. A broncoscopia, o lavado transtraqueal, broncoalveolar e o exame citológico por agulha fina podem ser úteis no diagnóstico, mas em muitos casos são inconclusivos (OGILVIE et al., 1989; McNIEL et al., 1997). Nos dois cães em que se realizou o exame radiográfico foi possível a visualização de nódulos no pulmão, mas o aumento de volume dos linfonodos observados na necropsia, não foi detectado radiograficamente.

Confirmada a presença de neoplasia pulmonar, um exame clínico minucioso deve ser realizado com o objetivo de diferenciar TPP de metástase. O estadiamento clínico TNM é necessário para determinar o prognóstico e estabelecer o tratamento ao qual o animal será submetido. Na maioria dos casos de TPP em cães, o nódulo tumoral é solitário e predominantemente localizado nos lobos caudais, sendo possível a realização da lobectomia. Diante da não visualização dos linfonodos intratorácicos no exame radiográfico e constatada a presença de massa passível de excisão cirúrgica, a avaliação dos linfonodos mediastínicos deve ser realizada durante a cirurgia (OGILVIE et al., 1989; McNIEL et al., 1997). Neste relato, nos casos 2 e 3 não foi realizado o estadiamento clínico TNM devido aos animais apresentarem graves alterações sistêmicas, impossibilitando a realização de exames complementares para investigar e diferenciar TPP de metástase.

Apesar de poderem ocorrer complicações póscirúrgicas como efusão pleural, infecção, hemotórax, pneumotórax, enfisema subcutâneo e megaesôfago, o tratamento cirúrgico deve ser realizado sempre que possível. Estudos mostram que cães submetidos à excisão cirúrgica do TPP tiveram uma sobrevida maior quando comparados com os cães não submetidos ao tratamento cirúrgico (OGILVIE et al., 1989; McNIEL et al., 1997; POLTON et al., 2008). Nos animais com TPP em estágios avançados, como nos casos 1 e 2, nos quais o tumor era difuso por todos os lobos e com presença de metástases, os quimioterápicos vindesina, cisplatina e navelbine mostraram resultados satisfatórios na manutenção da qualidade de vida do animal (WITHROW, 2007).

O carcinoma de células escamosas e o carcinoma anaplásico metastatizam com maior frequência que o adenocarcinoma e o carcinoma bronquialveoar (WILSON; DUNGWORTH, 2002), sendo que as metástases para locais distantes são menos relatadas em cães do que em gatos (OGILVIE et al., 1989; McNIEL et al., 1997). Em cães, as metástases dos TPP epiteliais foram descritas para os linfonodos intratorácicos, tecidos torácicos, intrapulmonares, olhos, costelas, adrenais e cérebro (OGILVIE et al., 1989; McNIEL et al., 1997; WILSON; DUNGWORTH, 2002; WITHROW, 2007). Apesar da possibilidade de ocorrerem metástases em outros locais além dos descritos acima, não há descrições prévias de metástase de TPP epitelial em pericárdio, coração, fígado, rins e glândula perianal como observado no presente relato. Tanto em humanos como em cães, os TPP malignos tendem a metastatizar para o sistema nervoso central 
(WILSON; DUNGWORTH， 2002; ARRIETA et al., 2011). Uma das causas relacionadas a essa predisposição é a mutação no gene egfr (epidermal growth fator receptor) (GILLETT et al., 1992).

A classificação e a graduação histopatológica tem influência na sobrevida do animal. Devido a dificuldade em determinar a origem do TPP epitelial, a classificação histopatológica é baseada no padrão histológico do tumor (OGILVIE et al., 1989; McNIEL et al., 1997; WITHROW, 2007). Os tumores que mais acometem os cães são o adenocarcinoma, o carcinoma bronquioloalveoar, e menos frequentemente o carcinoma de células escamosas e o carcinoma adenoescamoso. Tumores constituídos inteiramente ou predominantemente por arranjos papilares irregulares, acinares, sólidos ou glandulares mistos são classificados como adenocarcinoma. O carcinoma bronquioloalveolar é caracterizado por sua localização lobular periférica e por ser composto de arranjos que lembram alvéolos e epitélio bronquiolar. O carcinoma de células escamosas é constituído predominantemente por arranjos sólidos. As células epiteliais apresentam moderado a amplo citoplasma e núcleo redondo a ovalado. Queratinização e pontes intercelulares podem estar presentes. Tumores compostos por diferenciação escamosa e acinar são classificados como carcinoma adenoescamoso. Tumores combinados, carcinoma anaplásico, carcinoma de células grandes e carcinoma de células pequenas são tumores epiteliais pouco documentados em cães (WILSON; DUNGWORTH, 2002).

A graduação histológica avalia a diferenciação tumoral, o pleomorfismo celular, o índice mitótico, o tamanho nuclear, necrose, fibrose e a demarcação tumoral, sendo aplicada nos TPP epiteliais. Cães com TPP grau II e III tiveram uma sobrevida significativamente menor do que os cães com graduação I (OGILVIE et al., 1989; McNIEL et al., 1997). Nos três casos, o diagnóstico de TPP foi realizado pós-morte e as alterações histológicas observadas são compatíveis com grau II nos três tumores.
O exame imuno-histoquímico é muito utilizado para diferenciar neoplasias primárias pulmonares e confirmar o diagnóstico histopatológico. Para diferenciar tumores epiteliais de mesotelioma, usa-se o anticorpo anti-fator de transcrição da tireóide-1 (TTF-1) que apresenta marcação positiva nas células epiteliais e negativa nas mesoteliais. Os anticorpos anti-citoqueratina e antivimentina são utilizados para diferenciar tumores epiteliais de mesenquimais. No entanto, tanto em humanos como em cães, cerca de $40 \%$ dos TPP epiteliais apresentam marcação positiva para pancitoqueratina e vimentina. Acredita-se que isso ocorra devido à perda da estabilidade nas células epiteliais neoplásicas para que estas se disseminem pelo organismo (BURGESS; KERR, 2009). No presente trabalho, os TPP tinham origem epitelial e apresentaram marcação positiva para o anticorpo anti-pancitoqueratina e negativa para o anticorpo anti-vimentina. Tanto os achados histopatológicos como os imuno-histoquímicos dos três casos estão de acordo com a literatura (OGILVIE et al., 1989; McNIEL et al., 1997; WILSON; DUNGWORTH, 2002).

A ocorrência de TPP é incomum em cães, no entanto, a convivência entre cão e homem está cada vez mais próxima e consequentemente o animal está submetido a uma maior exposição a fatores carcinogênicos e possivelmente o desenvolvimento de TPP em cães tenderá a aumentar. O estadiamento clínico (TNM), a classificação e graduação histopatológica são fundamentais para o planejamento terapêutico e determinação do prognóstico de cães com TPP.

\section{Referências}

ARRIETA, O.; VILARREAL-GARZA, C.; ZAMORA, J.; BLAKE-CERDA, M.; MATA, M. D.; ZAVALA, D. G.; MUNIZ-HERNÁNDEZ, S.; GARZA, J. Lon-term survival in patients with non-small cell lung cancer and synchronous brain metastasis treated with whole-brain radiotherapy and thoracic chemoradiation. Radiation Oncology, v. 6, n. 166, p. 2-7, 2011. 
BURGESS, H. J.; KERR, M. E. Cytokeratin and vimentin co-expression in 21 canine primary pulmonary epithelial neoplasms. Journal of Veterinary Diagnostic Investigation, v. 21, n. 8, p. 815-820, 2009.

GILLETT, N. A.; STEGELMEIER, B. L.; KELLY, G.; HALEY, P. J.; HAHN, F. F. Expression of Epidermal Growth Factor Receptor in plutonium-239-induced lung neoplasms in dogs. Veterinary Pathology, USA, v. 29, n. 1, p. 46-52, 1992.

McNIEL, E. A.; OGILVIE, G. K.; POWERS, B. E.; HUTCHISON, J. M.; SALMAN, M. D.; WITHROW, S. J. Evaluation of prognostic factors for dogs with primary lung tumors: 67 cases (1985-1992). Journal of American Veterinary Medical Association, Illinois, v. 211, n. 11, p. 1422-1427, 1997.

NELSON, O. L.; SELLON, R. K. Pulmonary parenchymal disease. In: ETTINGER, S. J.; FELDMAN, E. C. (Ed.). Textbook of veterinary internal medicine. 6. ed. St Louis: Elsevier Saunders, 2005. v. 2, p. 1241-1244.

OGILVIE, G. K.; HASCHEK, W. M.; WITHROW, S. J.; RICHARDSON, R. C.; HARVEY, H. J.; HENDERSON, R. A.; FOWLER, J. D.; NORRIS, A. M.; TOMLINSON, J.; McCAW, D.; KLAUSNER, J. S.; RESCHKE, R. W.; McKIERNAN, B. C. Classification of primary lung tumors in dogs: 210 cases (1975-1985). Journal of American Veterinary Medical Association, Illinois, v. 195, n. 1, p. 106-112, 1989.
POLTON, G. A.; BREARLEY, M. J.; POWELL, S. M.; BURTON, C. A. Impact of primary tumour stage on survival in dogs with solitary lung tumours. Journal of Small Animal Practice, v. 49, n. 2, p. 66-71, 2008.

REIF, J. S., DUNN, K.; OGILVIE, G. K.; HARRIS, C. K. Passive smoking and canine lung cancer risk. American Journal Epidemiology, v. 135, n. 3, p. 234-239, 1992.

VOLLMER, E.; SCHULTZ, H.; STELLMACHER, F. L.; KAHLER, D.; ABDULLAH, M.; GALLE, J.; LANG, D. S.; GOLDMANN, T. Tumors in the lungmorphologic features and the challenge of integrating biomarker signatures into diagnostics. Romanian Journal of Morphologic and Embryology, v. 51, n. 4, p. 607-614, 2010.

WILSON, D. W.; DUNGWORTH, D. L. Tumors of the respiratory tract. In: MEUTEN, D. J. (Ed.). Tumors in domestic animals. 4. ed. Iowa: Blackwell Publishing Company, 2002. p. 380-392.

WITHROW, S. J. Tumors of the respiratory system. In: WITHROW, S. L.; VAIL, D. M. (Ed.). Withrow \& Mac Ewen's-Small Animal Clinical Oncology. 4. ed. St Louis: Saunders Elsevier, 2007. p. 517-25.

WOODS, J. M.; KORETZ, M. J. Emergency abdominal surgery for complications of metastatic lung carcinoma. Archives of Surgery, v. 125, n. 5, p. 583-585, 1990. 